\title{
An Effective Hybrid Algorithm for De-Speckling the Speckle Noise in SAR Images
}

\author{
Natteshan N V S, N. SureshKumar
}

\begin{abstract}
Image Processing has emerged as an essential lookup domain in circuit branches for quite a few decades. SAR is a type of Radar. It is connected to pics of articles like scene. It applies $e$ $S A R$ receiving wide development to the target for acquiring better spatial resolution than what is got through customary beam-scanning radars. In digital image processing field, processing Synthetic Aperture Radar is unexpectedly gaining focus. Very similar to all image processing methods, issues such as edge detection, enhancement and noise reduction are vital lookup troubles in SAR images also. Of late, speckle noise has emerged as a massive issue. Because of its presence, the SAR Images are classified as robust and multiplicative noises. Effecting speckle noise reduction in Synthetic Aperture Radar photographs is pretty challenging. Synthetic Aperture radar and its description is used in the utility of Flood prediction mapping. In this paper we implemented a better methodology for de-speckling Synthetic Aperture Radar imagery by way of using Fuzzy Discontinuity adaptive Non neighborhood potential filter. Application of fuzzy strategy to Importance sampling unscented kalman filter produces better end result than compared with fuzzy frost filter and also the TMAV and ATMAV produces higher end result therefore it can be a satisfactory filter for de-speckling.
\end{abstract}

Keywords: Fuzzy approach, SAR, de-speckling, unscented kalman filter.

\section{INTRODUCTION}

Synthetic Aperture radar is a always available satellite technology and it has a lots of advantage when compared with the traditional imaging satellites. One of the main merits synthetic aperture radar process is that it can penetrate haze, fog and mist and temperature cannot cause any hurdles to this satellite. But one of the troubles which this satellite has is the speckle noise which is a pattern of granular in nature due to the backscattering of the echo from earth which is the cause for such pattern. Hence this noise will definitely be a hurdle for further interest in processing the data. So in this work a mitigation methodology is proposed for removing this type of noise. First the input image with speckle noise is given to the fuzzy filter and it is further combined with the discontinuity adaptive non local means filter to provide good removal of speckle noise.

\section{LITERATURE REVIEW}

Speckle noise is a big issue in the Synthetic aperture radar images which reduces the further processing steps which includes classification or any further interpretation from the image. Here we see the various works carried out for removing the speckle noise from the input Synthetic aperture radar images. There are many speckle reduction techniques is presented in various studies. Generally we can classify the de-speckling techniques in the spatial and frequency domains. There are some works where there is a utilization of edge based features and target detection with the improvement in Non local Means in (W. Zhang, F. Liu 2010), (W. G. Zhang 2011). There is a utilization of non sub sampled shearlet transform for reducing the speckle noise by reducing the shrinkage which is not desirable. A comparison of various markov models in complex domain for removing the speckle noise in the Synthetic Aperture Radar image(B. Hou 2012). Recursive and mean shif filters are some alternative filters suggested by (Subrahmanyam G 2010),( Jarabo-Amores P 2009) for despekling the SAR images. Bayesian analysis is used in synthetic aperture radar images for removing the speckle noise based on model (Hebar M 2011). When it comes to preserving the edges and also removing the noise in the SAR image the discontinuity adaptive non local means provides better despeckling effect (Jojy C 2013) .There is also utilization of neuro fuzzy methods for finding out the noise which is impulsive in nature is presented also with some modifications (M.T. Yildirim,2008)( M.A. Soyturk,2011). A type II fuzzy system is utilized to remove the speckle noise from the input image (J. T. S. Sumantyo,2008).

\section{Fuzzy Discontinuity Adaptive Non Local Means Filter}

In this proposed work, we propose a methodology for removing the speckle noise and the steps involved in this work are depicted in Fig. 1. The input to this methodology consists of the ALOS PALSAR images and it is given to the fuzzy filter and later this output is utilized by the discontinuity adaptive Non local means filter to remove the noise from image and we obtain a image which is despeckled. All these steps are depicted in Fig. 1. 


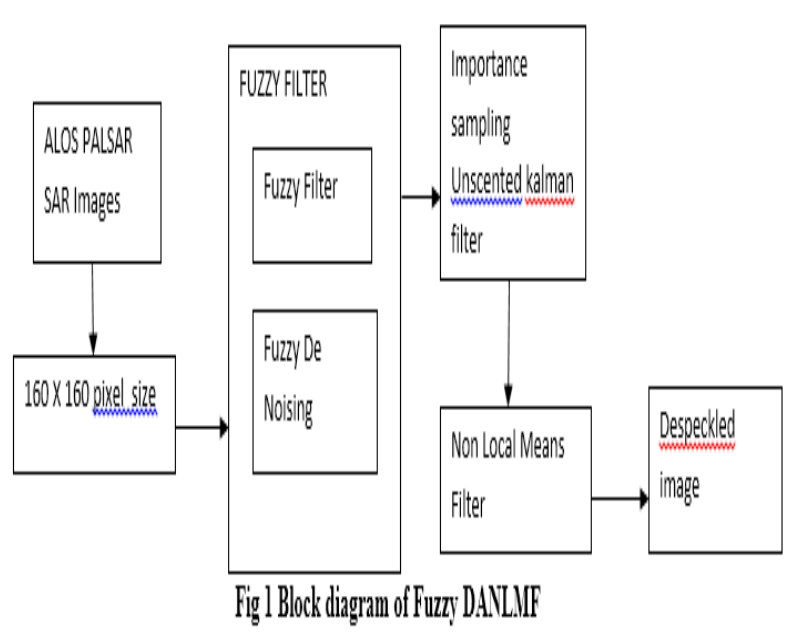

Fig 1 Block diagram of Fuzzy DANLMF 3. Performance Evaluation

In order to measure the performance of filter, four techniques have been used. Those techniques are Speckle Index (SI) and Equivalent Number of Looks (ENL) for speckle noise reduction performance evaluation. According to [18], the equivalent wide variety of appears (ENL) used to quantify the level to which the speckle is reduced in an ALOS-PALSAR image. According to [19], ENL is the estimator of speckle noise and is proportional to the range of depth values that are independent and is used in pixel per pixel basis and is defined as

$$
E N L=\frac{\operatorname{mean}\left(F^{2}\right)}{\operatorname{Var}\left(F^{2}\right)}
$$

It is the ratio to the measure of implies to popular deviation and is a computation of the signal-to-noise ratio. The greater of Equivalent Number of looks value, the more desirable the speckle reduction. Speckle Index is a computation of reduction of speckle noise in phrases of contrast which is average in the image and expressed as

$S I=\frac{1}{M N} \sum_{i=1}^{M} \sum_{i=1}^{N} \frac{\sigma(i, j)}{\mu(i, j)}$

The $(i, j)$ and $(i, j)$ are the standard deviation and capability corresponding to a neighbor domain, respectively. Maximal price of SI corresponds to distinctive image, and its minimal value corresponds to comparable images or improved image quality.

\section{EXPERIMENTAL ANALYSIS}

There are 4 fuzzy filters which are being utilized in the area of study, specifically two ATMED, ATMAV, TMED and TMAV. These filters will be combined with ISUKF-NLMF filter. Thus proposed filters are particularly ATMED+ ISUKF-NLMF, ATMAV+ ISUKF-NLMF, TMED+ ISUKF-NLMF and TMAV+ ISUKF-NLMF. Homogeneous and heterogeneous vicinity in Synthetic Aperture Radar images are the areas where these filters will be applicable. Its objectives are to determine how far the speckle noise is reduced in the main in homogeneous areas. Table 1 indicates that the performance of Fuzzy with frost filter in Heterogeneous Area. Table 2 shows that Performance measures of Fuzzy ATMAV with two ISUKF-NLMF. Table 3 two indicates two that Performance measures of Fuzzy ATMED with ISUKF-NLMF. Table 4 suggests that Performance measures of Fuzzy TMED with ISUKF-NLMF. Table 5 shows that Performance measures of Fuzzy TMAV with ISUKF-NLMF. From these consequences we can see that ATMAV+ISUKF-NLMF gives the high-quality results among all different filters. so that ATMAV+ISUKF-NLMF is a first-rate filter for despeckling. Table 6-11 are the same measures with different noise variance value.

Table I Performance measures for FUZZY-FROST FILTER in Heterogeneous Area

\begin{tabular}{|l|c|c|c|c|c|c|}
\hline$\sigma_{\bar{V}}^{2}=0.015$ & ENL & SI & MEAN & $\begin{array}{c}\text { STDE } \\
\mathrm{V}\end{array}$ & RMSE & S/MSE \\
\hline F+TMAV & $\mathbf{1 . 4 3 2}$ & $\mathbf{0 . 8 3 5 6 4 7}$ & 0.2730 & $\mathbf{0 . 2 2 8 1}$ & 0.334511 & 3.180678 \\
\hline F+TMED & 1.3279 & 0.867801 & 0.3484 & 0.3023 & 0.477153 & 0.110419 \\
\hline F+ATMAV & 0.56865 & 0.663055 & 0.3524 & 0.2337 & 0.416673 & 1.286066 \\
\hline $\begin{array}{l}\text { F+ATMED } \\
\text { FROST }\end{array}$ & 0.78926 & 1.125613 & 0.2240 & 0.2521 & 0.300556 & 4.136003 \\
\hline
\end{tabular}

Table II Performance measures for Fuzzy-ATMAV with ISUKF-NLMF

\begin{tabular}{|l|c|c|c|c|c|c|}
\hline$\sigma_{D}^{2}=0.015$ & ENL & S/MSE & RMSE & SSIM & FOM & EC \\
\hline $\begin{array}{l}\text { Euclidean } \\
\text { Distance }\end{array}$ & 156.7971 & 20.488368 & 0.046002 & 0.549341 & 0.82119 & 0.47789 \\
\hline $\begin{array}{l}\text { Manhattan } \\
\text { Distance }\end{array}$ & $\mathbf{2 8 2 . 0 9 4 8}$ & 20.846451 & 0.044297 & 0.416068 & 0.574057 & 0.63364 \\
\hline
\end{tabular}

Table III Performance measures Fuzzy ATMED with ISUKF-NLMF

\begin{tabular}{|l|c|c|c|c|c|c|}
\hline$\sigma_{D}^{2}=0.015$ & ENL & S/MSE & RMSE & SSIM & FOM & EC \\
\hline $\begin{array}{l}\text { Euclidean } \\
\text { Distance }\end{array}$ & 132.4391 & 17.391302 & 0.064085 & 0.480813 & 0.82221 & 0.40454 \\
\hline $\begin{array}{l}\text { Manhattan } \\
\text { Distance }\end{array}$ & $\mathbf{2 5 9 . 0 8 4 3}$ & 17.048065 & 0.066799 & 0.416068 & 0.82032 & 0.47048 \\
\hline
\end{tabular}

Table IV Performance measures of Fuzzy TMED with ISUKF-NLMF

\begin{tabular}{|l|c|c|c|c|c|c|}
\hline$\sigma_{D}^{2}=0.015$ & ENL & S/MSE & RMSE & SSIM & FOM & EC \\
\hline $\begin{array}{l}\text { Euclidean } \\
\text { Distance }\end{array}$ & 104.0938 & 15.444708 & 0.084495 & 0.418559 & 0.82209 & 0.41615 \\
\hline $\begin{array}{l}\text { Manhattan } \\
\text { Distance }\end{array}$ & $\mathbf{2 1 3 . 4 1 6 4}$ & 14.913050 & 0.089452 & 0.307906 & 0.81591 & 0.39747 \\
\hline
\end{tabular}

Table V Performance measures of Fuzzy TMAV with ISUKF-NLMF 


\begin{tabular}{|c|c|c|c|c|c|c|}
\hline$\sigma_{\mathrm{D}}^{2}=0.015$ & ENL & S/MSE & RMSE & SSIM & FOM & EC \\
\hline Euclidean Distance & 243.8301 & 17.203595 & 0.067363 & 0.391239 & 0.81687 & 0.44958 \\
\hline Manhattan Distance & $\mathbf{2 6 8 . 7 0 1 3}$ & 17.088492 & 0.068073 & 0.391399 & 0.81655 & 0.4615 \\
\hline
\end{tabular}

Table VI performance of Fuzzy with frost filter in Homogenous Area.

\begin{tabular}{|l|c|c|c|c|c|c|}
\hline$\sigma_{D}^{2}=0.01$ & ENL & SI & MEAN & STDEV & RMSE & S/MSE \\
\hline F+TMAV & $\begin{array}{c}\mathbf{1 4 . 4 8 8} \\
\mathbf{3}\end{array}$ & $\mathbf{0 . 2 6 2 7 1 9}$ & 0.4979 & $\mathbf{0 . 1 3 0 8}$ & 0.483534 & 3.100847 \\
\hline F+TMED & 2.4181 & 0.643079 & 0.5046 & 0.3245 & 0.649604 & 0.488170 \\
\hline F+ATMAV & 7.5215 & 0.182313 & 0.5127 & 0.0935 & 0.491023 & 2.960943 \\
\hline F+ATMED & 4.3009 & 0.482192 & 0.4541 & 0.2189 & 0.452566 & 3.656163 \\
\hline $\begin{array}{l}\text { ORIGINAL } \\
\text { FROST }\end{array}$ & 2.8393 & 0.593469 & 0.4426 & 0.2627 & 0.379220 & 5.169058 \\
\hline
\end{tabular}

Table VII Performance measures of FUZZY+FROST FILTER in Heterogeneous Area

\begin{tabular}{|l|c|c|c|c|c|c|}
\hline$\sigma_{\mathrm{D}}^{2}=0.01$ & ENL & SI & MEAN & $\begin{array}{c}\text { STDE } \\
\mathrm{V}\end{array}$ & RMSE & S/MSE \\
\hline F+TMAV & $\mathbf{0 . 5 6 2 3 7}$ & $\mathbf{1 . 3 3 3 4 9 2}$ & 0.1479 & $\mathbf{0 . 1 9 7 2}$ & 0.250145 & 2.425351 \\
\hline F+TMED & 2.483 & 0.634620 & 0.5030 & 0.3192 & 0.647311 & 0.585201 \\
\hline F+ATMAV & 0.19593 & 1.129581 & 0.2208 & 0.2494 & 0.331427 & 0.053722 \\
\hline F+ATMED & 4.211 & 0.487314 & 0.4488 & 0.2187 & 0.458055 & 3.555728 \\
\hline $\begin{array}{l}\text { ORIGINAL } \\
\text { FROST }\end{array}$ & 0.54746 & 1.351519 & 0.2195 & 0.2967 & 0.219422 & 6.865021 \\
\hline
\end{tabular}

Table VIII Performance measures of Fuzzy ATMAV with ISUKF-NLMF

\begin{tabular}{|l|c|c|c|c|c|c|}
\hline$\sigma_{D}^{2}=0.01$ & ENL & S/MSE & RMSE & SSIM & FOM & EC \\
\hline $\begin{array}{l}\text { Euclidean } \\
\text { Distance }\end{array}$ & 154.5227 & 20.590206 & 0.045662 & 0.999987 & 0.82237 & 0.48479 \\
\hline $\begin{array}{l}\text { Manhattan } \\
\text { Distance }\end{array}$ & $\mathbf{2 6 3 . 7 6 3 8}$ & 20.565490 & 0.045713 & 0.999987 & 0.82082 & 0.63691 \\
\hline
\end{tabular}

Table IX Performance measures of Fuzzy ATMED with ISUKF-NLMF

\begin{tabular}{|l|c|c|c|c|c|c|}
\hline$\sigma_{\bar{D}}^{2}=0.01$ & ENL & S/MSE & RMSE & SSIM & FOM & EC \\
\hline $\begin{array}{l}\text { Euclidean } \\
\text { Distance }\end{array}$ & 134.0007 & 17.355805 & 0.064523 & 0.999974 & 0.82173 & 0.40442 \\
\hline $\begin{array}{l}\text { Manhattan } \\
\text { Distance }\end{array}$ & $\mathbf{2 6 0 . 2 5 3 3}$ & 17.103652 & 0.066414 & 0.999973 & 0.82465 & 0.46091 \\
\hline
\end{tabular}

Table X Performance measures of Fuzzy TMED with ISUKF-NLMF

\begin{tabular}{|c|c|c|c|c|c|c|}
\hline$\sigma_{\mathbb{W}}^{2}=0.01$ & ENL & S/MSE & RMSE & SSIM & FOM & EC \\
\hline Euclidean Distance & 111.61 & 15.38779 & 0.08481 & 0.99995 & 0.8217 & 0.4055 \\
& 5 & 1 & 9 & 6 & 2 & 6 \\
& & & & & & \\
\hline
\end{tabular}

Published By:

Blue Eyes Intelligence Engineering \& Sciences Publication

\section{ISUKF-NLMF}

\begin{tabular}{|l|c|c|c|c|c|c|}
\hline$\sigma_{D}^{2}=0.01$ & ENL & S/MSE & RMSE & SSIM & FOM & EC \\
\hline $\begin{array}{l}\text { Euclidean } \\
\text { Distance }\end{array}$ & 141.2456 & 17.394420 & 0.065695 & 0.999974 & 0.8221 & 0.40474 \\
\hline $\begin{array}{l}\text { Manhattan } \\
\text { Distance }\end{array}$ & $\mathbf{2 4 5 . 4 2 4 4}$ & 17.299173 & 0.066640 & 0.999973 & 0.81976 & 0.45685 \\
& & & & & & \\
\hline
\end{tabular}

\section{CONCLUSION}

The end result indicates that Fuzzy strategy have robustness to decrease speckle noise in SAR image, via the aggregate Fuzzy-ATMAV, operate better performance than different filters. This filters applied in each three Homogeneous and Heterogeneous areas of ALOSPALSAR image, with home windows dimension $3 \times 3$ filters. ATMAV+ISUKF-NLMF two filter generally generates the exceptional value for ENL, SI and Standard Deviation price than different filters. Fuzzy ISUK-NLM produces higher result than compared with fuzzy frost filter. And also the ATMAV produces higher result therefore it can be a excellent filter for despeckling. With this advantage, ATMAV+ISUKF-NLMF filter can use for ALOS-PALSAR information processing which requires readability of the image.

\section{REFERENCES}

1. W. Zhang, F. Liu, L. Jiao, B. Hou, S. Wang, and R. Shang 'SAR image de-speckling using edge detection and feature clustering in Bandelet domain', IEEE Geosci. Remote Sens. Lett, 7(1), pp. 131-135 (2010)

2. W. G. Zhang and Q. Zhang, 'SAR image de-speckling combining target detection with improved non local means', Electron. Lett, 47(12), pp. 724-725 (2011)

3. B. Hou, X. Zhang, X. Bu, and H. Feng, 'SAR image despeckling based on nonsubsampled shearlet transform', IEEE J. Sel. Top. Appl. Earth Observ. Remote Sens, 5(3), pp. 809-823 (2012)

4. D. Gleich (2012) 'Markov random field models for non-quadratic regularization of complex SAR images', IEEE J. Sel. Top. Appl. Earth Observ. Remote Sens.,5(3), pp. 952-961 (2012)

5. Chitroub S, Houacine A, Sansal B 'Statistical characterization and modeling of SAR images. Signal Processing' 82(1), pp. 69-92 (2002)

6. Achim A, Kuruoglu EE, Zerubia J 'SAR image filtering based on the heavy-tailed Rayleigh model', IEEE Trans Image Process, 15(9), pp. 2686-93 (2006)

7. Bianchi T, Argenti F, Alparone L 'Segmentation-based map despeckling of SAR images in the undecimated wavelet domain', IEEE Trans Geoscience and Remote Sensing, 46(9), 2728-42. (2008)

8. Subrahmanyam G, Rajagopalan AN, Aravind R 'A recursive filter for despeckling SAR images', IEEE Trans Image Processing, 17(10),pp.1969-74, (2010) 
9. Jarabo-Amores P, Rosa-Zurera M, Mata-Moya D, Vicen-Bueno R 'Mean-Shift filtering to reduce speckle noise in SAR images', IEEE Instrumentation and Measurement Technology Conference, pp 1188-93. (2009)

10. Hebar M, Gleich D, Cucej Z. 'Autobinomial model for SAR image despeckling and information extraction', IEEE Trans Geosci Rem Sens, 47(12) (2011)

11. Jojy C, Nair MS, Subrahmaniyam GRKS, Riji R. 'Discontinuity adaptive non-local means with importance sampling unsented Kalman filter for despeckling SAR images', IEEE Transaction on selected topics in Applied Earth Observa-tion And Remote Sensing, 6(4) (2013)

12. M.E. Yuksel, E. Besdok 'A hybrid neuro-fuzzy filter for edge preserving restoration of images corrupted by impulse noise', 15, pp. 928-936 (2004)

13. M.T. Yildirim, A. Basturk, M.E. Yuksel 'Impulse noise removal from digital images by a detail-preserving filter based on type-2 fuzzy logic', 16, pp.920-928 (2008)

14. Y. Yuksel 'Performance enhancement of image impulse noise filters by image rotation and fuzzy processing', International Journal of Electronics and Communications,pp.329-338 (2010)

15. M.A. Soyturk, A. Basturk, M.E. Yuksel 'Rule based optimization of type-2 fuzzy inference system used at impulse noise removing', IEEE Conference on Signal Processing and Communications Applications,pp. 833-836 (2011)

16. M.E. Yuksel, A. Basturk 'Application of type-2 fuzzy logic filtering to reduce noise in color images', IEEE Computational Intelligence Magazine,7, pp.25-35 (2012)

17. J. T. S. Sumantyo and J. Amini 'A model for removal of speckle noise in SAR images (ALOS PALSAR)' J. Remote Sens., 34(6),pp.503-516. (2008)

18. L. Gagnon and A. Jouan 'Speckle Filtering of SAR Images - A Comparative Study Between Complex-Wavelet-Based and Standard Filters', Proceedings of SPIE, pp. 80-91 (1997) 